\title{
BMJ Open The association between patients' beliefs about medicines and adherence to drug treatment after stroke: a cross-sectional questionnaire survey
}

\author{
Maria Sjölander, ${ }^{1,2}$ Marie Eriksson, ${ }^{3}$ Eva-Lotta Glader ${ }^{1}$
}

To cite: Sjölander M, Eriksson M, Glader E-L. The association between patients beliefs about medicines and adherence to drug treatment after stroke: a cross-sectional questionnaire survey. BMJ Open 2013;3:e003551. doi:10.1136/bmjopen-2013003551

- Prepublication history for this paper is available online. To view these files please visit the journal online (http://dx.doi.org/10.1136/ bmjopen-2013-003551).

Received 4 July 2013 Revised 20 August 2013 Accepted 21 August 2013

\footnotetext{
${ }^{1}$ Department of Public Health and Clinical Medicine, Umeå University, Umeå, Sweden 2Department of Pharmacology and Clinical Neuroscience, Umeå University, Umeå, Sweden ${ }^{3}$ Department of Statistics, Umeå School of Business and Economics, Umeå University, Umeå, Sweden
}

\section{Correspondence to} Ms Maria Sjölander; maria.sjolander @pharm.umu.se

\section{ABSTRACT}

Objectives: Adherence to preventive drug treatment is a clinical problem and we hypothesised that patients' beliefs about medicines and stroke are associated with adherence. The objective was to examine associations between beliefs of patients with stroke about stroke and drug treatment and their adherence to drug treatment. Design: Cross-sectional questionnaire survey. Setting: Patients with stroke from 25 Swedish hospitals were included.

Measurements: Questionnaires were sent to 989 patients to assess their perceptions about stroke (Brief IIIness Perception Questionnaire, Brief IPQ), beliefs about medicines (Beliefs about Medicines Questionnaires, BMQ) and adherence to treatment (Medication Adherence Report Scale, MARS) 3 months after stroke onset. Only patients living at home were included in the analysis. The primary outcome was self-reported adherence as measured on MARS. MARS scores were dichotomised into adherent/ non-adherent. Background and clinical data from the Swedish Stroke register were included.

Results: 811 patients were still living at home and 595 answered the questionnaire. Complete MARS data were available for 578 patients and $72(12.5 \%)$ of these were classified as non-adherent. Non-adherent patients scored lower on positive beliefs as measured on BMQ-necessity (OR $=0.90,95 \% \mathrm{Cl} 0.83$ to 0.98) and BMQ-benefit (OR=0.77, 95\% Cl 0.68 to 0.87 ), and higher on negative beliefs as measured on $B M Q$-concern $(O R=1.12,95 \% \mathrm{Cl}$ 1.05 to 1.21$)$, BMQ-overuse ( $\mathrm{OR}=1.29,95 \% \mathrm{Cl} 1.14$ to 1.45), and $B M Q$-harm (OR=1.12, 95\% $\mathrm{Cl} 1.01$ to 1.24). The Brief IPQ showed that non-adherent patients believed their current treatment to be less useful $(p=0.001)$.

Conclusions: This study showed associations between beliefs of Swedish patients with stroke about medicines and adherence. Positive beliefs were less common and negative more common among non-adherent. To improve adherence, patients' beliefs about medicines should be considered.

\section{INTRODUCTION}

Stroke is the third leading cause of death in Sweden and causes great suffering among

\section{ARTICLE SUMMARY}

Strengths and limitations of this study

- Validated questionnaires have been used to collect data on a large sample of patients.

- Although only a minority of patients reported non-adherent behaviour, associations between beliefs and adherence were statistically significant.

- The cross-sectional design made it impossible to draw conclusions about causality.

survivors and claims vast amounts of resources. Preventive treatment is of great importance and secondary preventive drug treatment is recommended to most patients with stroke to prevent recurrent strokes. ${ }^{1}$ Patients' adherence to prescribed long-term and/or preventive treatment has, however, been shown to be $\operatorname{low}^{2}$ and this results in poor treatment outcomes in non-adherent patients. $^{3}$ A previous study on Swedish patients with stroke showed that between $25 \%$ and $50 \%$ of patients, depending on the type of drug, discontinue secondary preventive drug treatment within 2 years after a stroke. $^{4}$

Many factors have been tested for predictability of adherence. ${ }^{5}$ Some treatment or healthcare related factors, such as simplified dosage regimens or satisfaction with healthcare, have been found to associate with a higher degree of adherence. It has been more difficult to find consistent associations between demographics and psychosocial factors and adherence, possibly because of interactions between factors. ${ }^{5}$

Several theoretical models have been developed to explain associations between psychological factors and health-related behaviour in general and adherence behaviour specifically. The model most often discussed in relation to patient adherence is Howard 
Leventhal's self-regulatory model (SRM) ${ }^{6}$ According to an extended version of the SRM, both beliefs about medicines and illness perceptions are related to adherence. $^{7-9}$ Non-adherence is often assumed to be involuntary or unintentional-that patients forget, are unable to handle, or cannot afford the drug-but non-adherence is also quite often based on a decision, sometimes called 'intentional non-adherence'. ${ }^{10}$ Intentional nonadherence is based on personal beliefs of possible risks from the disease itself, possible risks from the treatment and with perceived need of the treatment.

Interventions to improve patients' long-term use of drugs are, although often complex, not very effective. ${ }^{11}$ Preventive drug therapy after stroke is a long-term and asymptomatic treatment and to improve adherence it might be important to consider patients' beliefs about medicines and stroke. We hypothesised that patients' beliefs about medicines and stroke are associated with drug adherence among patients with stroke. The objectives of this study were to examine beliefs of patients with stroke about stroke and drug treatment after stroke and to investigate if these beliefs are associated with patients' adherence to drug treatment after stroke.

\section{METHODS}

In this cross-sectional study, questionnaire data on attitudes and beliefs about stroke and medicines have been merged with clinical data from the Swedish stroke register (Riks-Stroke). The study questionnaire and the follow-up questionnaire from the stroke register were sent to the patients 3 months after stroke onset.

The participants in this study were all patients with stroke who were registered in Riks-Stroke from December 2011 to March 2012. Riks-Stroke was established in 1994 and since 1998 all hospitals that admit patients with acute stroke report to the register. ${ }^{12}$ In 2011 , the register was estimated to cover $90.5 \%$ of all stroke cases in Sweden. All 74 hospitals participating in the stroke register were invited to participate and 25 of the hospitals volunteered. The participating hospitals are situated in 15 of the 21 counties/regions in Sweden and represent rural and urban areas. University hospitals $(n=4)$, large non-university hospitals $(n=11)$ and community hospitals $(n=10)$ were included.

Only patients who, according to the stroke register, were living at home 3 months after they had suffered their stroke were included in the study. For other patients, such as patients living in institutions, nonindividual routines were assumed to have too much of an effect on patient adherence.

Background information on the patient and information about the stroke event was obtained from Riks-Stroke through the patient's personal identification number. Intracerebral haemorrhages, cerebral infarctions and strokes not specified as haemorrhage or infarction (diagnosis codes ICD-10: I61, I63 and I64) are included in Riks-Stroke. The register contains patient- related information and data about care from the acute phase of the stroke and from a 3-month follow-up questionnaire.

Data on patients' beliefs about stroke, medicines and patient adherence to treatment were collected through a questionnaire consisting of 35 questions with answers on Likert-type scales. The following three validated questionnaires were used in our study: the Brief Illness Perception Questionnaire (Brief IPQ), the Beliefs about Medicines Questionnaires (BMQ) and the Medication Adherence Report Scale (MARS).

The Brief IPQ consists of nine questions aimed at examining patients' cognitive and emotional ideas about their disease. ${ }^{13}$ The Brief IPQ has been tested in several illness groups and shows reliability and validity. ${ }^{13}$ For this study, questions have been modified to be more specific to stroke (eg, replacing the word 'illness' with 'stroke'), and the face validity of the translation to Swedish was tested on a sample of Swedish patients with stroke. The answers to the first eight questions in the Brief IPQ that were used in this study (table 1 ) were rated on a scale from 0 to 10 . The last question in the Brief IPQ is openended to assess what patients believe are the three most important causes of their stroke, but this question would have required qualitative analysis and, therefore, was not used.

The BMQ has been developed to assess personal beliefs about medicines. ${ }^{14}{ }^{15}$ BMQ-Specific assesses patients' beliefs about drugs prescribed for their personal use and BMQ-General assesses beliefs about medicines in general. The BMQ-Specific has two subscales (necessity and concern) with five questions each and the BMQ-General has three subscales (harm, overuse and benefit) with four questions each. Representations of the

Table 1 Back-translation of the questions in the modified Brief IIIness Perception Questionnaire

\begin{tabular}{|c|c|}
\hline $\begin{array}{l}\text { Question } \\
\text { number }\end{array}$ & $\begin{array}{l}\text { Back-translation of the questions in } \\
\text { the modified Brief Illness Perception } \\
\text { Questionnaire }\end{array}$ \\
\hline 1 & $\begin{array}{l}\text { How much does your stroke affect your } \\
\text { life? }\end{array}$ \\
\hline 2 & $\begin{array}{l}\text { How long do you think your stroke will } \\
\text { affect you? }\end{array}$ \\
\hline 3 & $\begin{array}{l}\text { How much control do you feel you have } \\
\text { over your stroke/stroke symptoms? }\end{array}$ \\
\hline 4 & $\begin{array}{l}\text { How much do you think your treatment } \\
\text { can prevent another stroke? }\end{array}$ \\
\hline 5 & $\begin{array}{l}\text { How much do you experience symptoms } \\
\text { from your stroke? }\end{array}$ \\
\hline 6 & $\begin{array}{l}\text { How concerned are you about having } \\
\text { another stroke? }\end{array}$ \\
\hline 7 & $\begin{array}{l}\text { How much do you think you know about } \\
\text { stroke? }\end{array}$ \\
\hline 8 & $\begin{array}{l}\text { How much does your stroke affect you } \\
\text { emotionally? (eg, does it make you angry, } \\
\text { scared, upset or depressed?) }\end{array}$ \\
\hline
\end{tabular}




$\begin{aligned} & \text { Table } 2 \\
& \text { subscales used to assess patients' beliefs about } \\
& \text { medicines }\end{aligned}$
\begin{tabular}{ll} 
BMQ-Subscales & Representation of personal beliefs \\
\hline $\begin{array}{l}\text { BMQ-Specific } \\
\text { Necessity }\end{array}$ & $\begin{array}{l}\text { Perceived personal need for medicine } \\
\text { to maintain or improve own health }\end{array}$ \\
Concern & $\begin{array}{l}\text { Perceived concern about negative } \\
\text { effects of their own use of medicines }\end{array}$ \\
BMQ-General & $\begin{array}{l}\text { Perceived harmful nature of medicines } \\
\text { in general }\end{array}$ \\
Overuse & $\begin{array}{l}\text { Perceived notion that doctors overuse } \\
\text { or put too much trust in medicines }\end{array}$ \\
Benefit & $\begin{array}{l}\text { Perceived potential benefits of } \\
\text { medicines in general }\end{array}$ \\
\hline BMQ, Beliefs about & Medicines Questionnaires.
\end{tabular}

different BMQ subscales are presented in table 2. Answers to all 22 questions were scored on a 5-point Likert scale (1=strongly disagree, 2=disagree, 3=uncertain, 4=agree, $5=$ =strongly agree) and a total score per BMQ scale was calculated. For individuals with one or more answers missing, the total scores of the corresponding BMQ subscales were excluded.

Self-rated non-adherence to treatment was the main outcome of this study and this was assessed using the 5-item version of the MARS. ${ }^{16}$ MARS and BMQ have previously been translated into Swedish with back-translation approved by the developer of the original questionnaires. The MARS-5 consists of five general statements about nonadherent behaviour (I forget to take my medicines, I alter the dose of my medicines, I stop taking my medicines for a while, I decide to miss out a dose, I take less than instructed) answered on a 5-point Likert scale (1=always, 2=often, 3=sometimes, 4=rarely, $5=$ never . The outcome variable was calculated as the total score on the MARS-5 and a score of 5-22 was considered non-adherent and a score of 23-25 was considered adherent. Sensitivity analyses were performed with MARS scores 21 and 20 as the cut-off for non-adherence. Individuals missing one or more answers on the MARS were excluded from the analysis because their total MARS score would not be comparable with the rest of the study population.

\section{Power calculation}

The main hypothesis of the study was that there is a difference in BMQ between adherent and non-adherent patients as defined by their MARS score. Including 388 individuals, of whom approximately half are adherent, gives the study $80 \%$ power to detect a difference of 0.2 (BMQ) between adherent and non-adherent patients if the SD for the difference is 0.7 . This calculation is based on a two-tailed t test and a significance level of 0.05 . To compensate for an ordinal response variable (BMQ) and a possible non-response (up to $40 \%$ ), at least 650 individuals needed to be sent a questionnaire.

\section{Statistical analyses}

Differences in background and medical factors were tested using the $\chi^{2}$ test. The factors tested were age, sex, type of stroke, low level of consciousness at admission to hospital, history of stroke and stroke unit treatment, and the factors from the 3-month follow-up were living alone, smoking, self-reported bad general health, self-reported depression, whether dependent on help and/or support from relatives, having had a return visit to a doctor and/or nurse and self-reported difficulties with memory. Age was coded as $<75$ years or $\geq 75$ years, sex as 'Man' or 'Woman', type of stroke as 'Haemorrhage' or 'Other', and difficulties with memory as 'Never/almost never', 'Sometimes' and 'Often/constantly'. Answers to all other factors were coded 'No' or 'Yes'. Factors with a statistically significant difference $(p<0.05)$ between adherent and non-adherent patients were included in multivariable analyses.

The results for individual Brief IPQ questions and BMQ subscales were calculated as medians and IQR. Mann-Whitney $U$ tests were used to test differences between adherent and non-adherent patients in illness perceptions (individual items in the Brief IPQ) and beliefs about medicines (BMQ subscales).

Besides descriptive analyses with group comparisons, the statistical analysis also included multivariable methods to control for several factors simultaneously. The outcome measure (self-reported adherence as measured with MARS) was dichotomised and logistic regression was used for multivariable analyses. For categorical covariables, '<75 years', 'Man', 'Haemorrhage', 'Never/ almost never' having difficulties with memory, and 'No' were chosen as reference categories. After checking the linearity assumption, the Brief IPQ scores and the BMQ scores were included as continuous covariates in the logistic regression models. Results are presented as OR with $95 \%$ CI. Only one BMQ scale at a time was included in the regression models because the objective was to study associations between different beliefs about medicines and adherence. Spearman's correlation coefficient was used to test for correlations between the different BMQ subscales.

An analysis of non-responders was performed using data from the stroke register. Non-responders were compared by $\chi^{2}$ test to responders in regards to the same background and medical factors as described above.

Internal consistency within BMQ subscales and MARS was measured with Cronbach's $\alpha$. A high value indicates high intercorrelation between items in a subscale and values over 0.7 are considered acceptable. ${ }^{17}$

Statistical analyses were performed using IBM SPSS Statistics V.21.0

\section{RESULTS}

The study questionnaire was sent to 989 patients who were discharged from hospital to their own homes. Of these, 811 were living at home 3 months after their stroke and were included for further analysis. Out of these 811, 595 
Figure 1 Flowchart of hospitals and patients in the study.

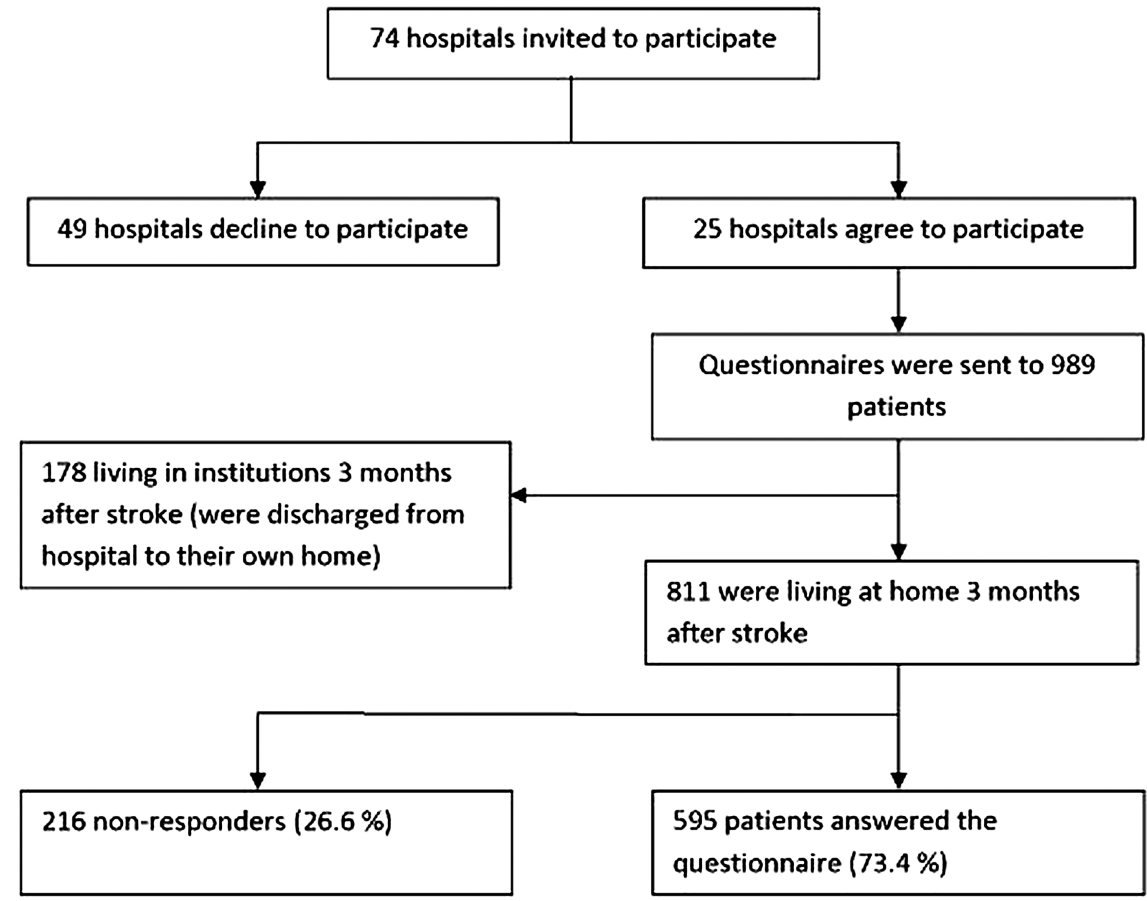

(73.4\%) responded to the questionnaire. Figure 1 shows a flowchart of hospitals and patients in the study.

Five hundred and seventy-eight patients had complete answers to the adherence questions (MARS) and 72 $(12.5 \%)$ of these were classified as non-adherent. The proportion of patients who self-reported non-adherent behaviour (the answers 'sometimes', 'often', and 'always') on any of the MARS statements were $9.7 \%$ for 'I forget to take my medicines', $12.8 \%$ for 'I alter the dose of my medicines', $2.2 \%$ for 'I stop taking my medicines for a while', $8.4 \%$ for 'I decide to miss out on a dose' and $4.5 \%$ for 'I take less than instructed'.

Differences in background and medical factors between adherent and non-adherent patients are presented in table 3. Non-adherent patients were more often men, not treated in stroke units, dependent on the help and support from relatives, had a history of stroke and more often self-reported memory difficulties compared to adherent patients.

Internal consistency for BMQ subscales and MARS, measured by Cronbach's $\alpha$, showed highest values for the BMQ-Specific scales (table 4).

Results from question 4 on the modified Brief IPQ 'How much do you think your current treatment can prevent another stroke?' showed that non-adherent patients believed their current treatment to be less useful (median=5 (IQR 3-7)) compared to adherent patients (median=7 (IQR 5-8)) and this difference was statistically significant $(\mathrm{p}=0.001)$. No other Brief IPQ-question showed a significant difference between adherent and non-adherent patients.

Results for total BMQ scale scores are presented and compared in table 5. All BMQ subscales except Necessity showed statistically significant differences between adherent and non-adherent patients in the univariate analysis.

The multivariable logistic regression models showed associations between all five subscales on beliefs about medicines and non-adherence to treatment. Non-adherent patients with stroke had lower scores on the positive statements about medicines as measured on BMQ subscales Necessity ( $\mathrm{OR}=0.90,95 \%$ CI 0.83 to 0.98 ) and Benefit $(\mathrm{OR}=0.77,95 \%$ CI 0.68 to 0.87$)$. Non-adherent patients also scored higher on the negative beliefs as measured on BMQ subscales Concern $(\mathrm{OR}=1.12$, $95 \%$ CI 1.05 to 1.21$)$, Harm (OR=1.12, $95 \%$ CI 1.01 to 1.24 ) and Overuse ( $\mathrm{OR}=1.29,95 \%$ CI 1.14 to 1.45$)$. Correlations between the different BMQ subscales were statistically significant except between Necessity and Concern (table 6).

Out of the 356 non-responders, 216 were still living at home 3 months after the stroke onset. Patients who responded to the questionnaire were compared to nonresponders in terms of background and medical factors (the same factors were tested as in table 3). The results of this analysis showed that non-responders more often had a history of stroke $(\mathrm{p}=0.018)$, self-reported bad general health $(p=0.001)$, depression $(p=0.012)$, were living alone $(p=<0.001)$ and were smoking $(p=0.046)$. Non-responders had been treated in university hospitals $(n=27)$, large non-university hospitals $(n=140)$ and community hospitals $(n=49)$.

The variables from Riks-Stroke with the highest numbers of missing data were, for responders $(n=595)$, return visits $(n=28)$ and self-reported depression $(n=22)$ and for non-responders $(n=216)$, return visits $(n=18)$ and self-reported depression $(n=14)$. 
Table 3 Patient characteristics by level of adherence. $\chi^{2}$ test of differences between non-adherent and adherent patients

\begin{tabular}{|c|c|c|c|}
\hline Variable/characteristic & Non-adherent $(\mathrm{n}=72)$ & Adherent $(n=506)$ & p Value \\
\hline Age (years), n (\%) & & & 0.341 \\
\hline$<75$ & $38(11.3)$ & $297(88.7)$ & \\
\hline$\geq 75$ & $34(14.0)$ & $209(86.0)$ & \\
\hline Sex, n (\%) & & & 0.042 \\
\hline Men & $51(14.7)$ & $295(85.3)$ & \\
\hline Women & $21(9.1)$ & 211 (90.9) & \\
\hline Type of stroke, n (\%) & & & 0.325 \\
\hline Haemorrhage & $3(7.5)$ & 37 (92.5) & \\
\hline Other (ICD10 I63+164) & $69(12.8)$ & 469 (87.2) & \\
\hline Low level of consciousness at admission, $\mathrm{n}(\%)$ & & & 0.770 \\
\hline No & $68(12.4)$ & $480(87.6)$ & \\
\hline Yes (drowsy or unconscious) & $4(14.3)$ & $24(85.7)$ & \\
\hline History of stroke, n (\%) & & & 0.010 \\
\hline No & $54(11.0)$ & $437(89.0)$ & \\
\hline Yes & $18(20.9)$ & $68(79.1)$ & \\
\hline Treated in stroke unit, n (\%) & & & 0.016 \\
\hline No & $6(30.0)$ & $14(70.0)$ & \\
\hline Yes & $66(11.8)$ & 491 (88.2) & \\
\hline \multicolumn{4}{|l|}{3 months follow-up } \\
\hline Living alone, n (\%) & & & 0.241 \\
\hline No & $45(11.2)$ & $357(88.8)$ & \\
\hline Yes & $25(14.7)$ & $145(85.3)$ & \\
\hline Smoking, n (\%) & & & 0.303 \\
\hline No & $64(12.1)$ & $463(87.9)$ & \\
\hline Yes & $8(17.4)$ & $38(82.6)$ & \\
\hline Self-reported bad general health, n (\%) & & & 0.210 \\
\hline No & $56(11.6)$ & $426(88.4)$ & \\
\hline Yes & $14(16.5)$ & 71 (83.5) & \\
\hline Self-reported depression, n (\%) & & & 0.147 \\
\hline No & $51(11.4)$ & $396(88.6)$ & \\
\hline Yes & $18(16.5)$ & $91(83.5)$ & \\
\hline Dependent on help/support from relatives, $n(\%)$ & & & 0.015 \\
\hline No & $26(9.0)$ & $263(91.0)$ & \\
\hline Yes & $43(15.8)$ & $230(84.2)$ & \\
\hline Return visit, $\mathrm{n}(\%)$ & & & 0.521 \\
\hline No & $7(9.9)$ & $64(90.1)$ & \\
\hline Yes & $60(12.5)$ & $419(87.5)$ & \\
\hline Difficulties with memory, $\mathrm{n}(\%)$ & & & 0.014 \\
\hline Never or almost never & $25(11.1)$ & $200(88.9)$ & \\
\hline Sometimes & $29(10.7)$ & 241 (89.3) & \\
\hline Often or constantly & $17(23.0)$ & $57(77.0)$ & \\
\hline
\end{tabular}

Table 4 Descriptive of questionnaire scales used

\begin{tabular}{llll}
\hline Scale & Number of items in scale & Range of scores & Cronbach's $\boldsymbol{\alpha}$ \\
\hline BMQ-Specific & & & 0.823 \\
Necessity & 5 & $5-25$ & 0.818 \\
Concern & 5 & $5-25$ & 0.684 \\
BMQ-General & 4 & $4-20$ & 0.647 \\
Overuse & 4 & $4-20$ & 0.697 \\
Harm & 4 & $4-20$ & 0.723 \\
Benefit & 5 & $5-25$ & \\
MARS & & & \\
\hline
\end{tabular}

BMQ, Beliefs about Medicines Questionnaires.

MARS, Medication Adherence Report Scale. 
Table 5 Scale score medians and IQR for the scales used to assess patients' beliefs about medicines (BMQ), comparing non-adherent with adherent patients

\begin{tabular}{|c|c|c|c|c|c|}
\hline \multirow[b]{2}{*}{ Variable } & \multirow[b]{2}{*}{$\begin{array}{l}\text { Valid cases } \\
(n=578)\end{array}$} & \multicolumn{2}{|c|}{ Scale score median (IQR) } & \multirow{2}{*}{$\begin{array}{l}\text { Mann-Whitney U } \\
\text { test } \\
\text { (p Value) }\end{array}$} & \multirow{2}{*}{$\begin{array}{l}\text { Adjusted with multivariable } \\
\text { logistic regression* } \\
\text { OR for a one-unit increase }(95 \% \\
\mathrm{Cl})\end{array}$} \\
\hline & & $\begin{array}{l}\text { Non-adherent } \\
(n=72)\end{array}$ & $\begin{array}{l}\text { Adherent } \\
(n=506)\end{array}$ & & \\
\hline \multicolumn{6}{|c|}{ BMQ-Specific } \\
\hline Necessity & 558 & $18(16-20)$ & $19(17-21)$ & 0.079 & 0.90 (0.83 to 0.98$)$ \\
\hline Concern & 552 & $14(11-17)$ & $12(9-15)$ & $<0.001$ & $1.12(1.05$ to 1.21$)$ \\
\hline \multicolumn{6}{|c|}{ BMQ-General } \\
\hline Overuse & 556 & $13(11-14)$ & $11(10-13)$ & $<0.001$ & $1.29(1.14$ to 1.45$)$ \\
\hline Harm & 544 & $11(9-12.25)$ & $10(8-12)$ & 0.038 & $1.12(1.01$ to 1.24$)$ \\
\hline Benefit & 560 & $16(14-16)$ & $16(15-18)$ & $<0.001$ & 0.77 (0.68 to 0.87$)$ \\
\hline
\end{tabular}

Sensitivity analyses with lower MARS scores (21 and 20) as the cut-off for non-adherence showed lower levels of non-adherence $(8.8 \%$ and $5.7 \%$, respectively) and fewer statistically significant differences in patient characteristics between adherent and non-adherent patients. Differences in BMQ between adherent and nonadherent patients remained with both cut-offs except for BMQ-Concern and BMQ-Harm when a MARS score of 20 was used as the cut-off (data not shown).

\section{DISCUSSION}

This study showed associations between patients' beliefs about stroke and medicines and self-rated nonadherence to drug treatment. Only $12.5 \%$ of patients were classified as non-adherent 3 months after stroke. Beliefs about medicines showed stronger associations to adherence compared to illness perceptions and nonadherent patients scored lower on positive beliefs about medicines and higher on negative beliefs.

Because having a stroke is often a serious and frightening experience, a low level of non-adherence to preventive drugs is expected only 3 months after stroke. Among the minority of patients reporting non-adherent behaviour, we showed an association between personal beliefs and adherence relatively soon after stroke. This indicates that patients who self-reported non-adherence early were patients for whom non-adherence was based on personal beliefs in medication harm and low beliefs in personal need for drugs.

Validated questionnaires have been used to collect data on a rather large sample of patients. None of the questionnaires have been validated specifically for stroke, but MARS and BMQ have been used in studies of a range of conditions that included stroke ${ }^{9} \quad 18 \quad 19$ and Brief IPQ has been tested in myocardial infarction and diabetes. ${ }^{13}$ The study had a high power. The power calculation estimated that the questionnaire had to be sent to at least 650 patients. Because all hospitals were invited, and the number and size of volunteering hospitals were not known in advance, those volunteering made it possible to include more than 650 patients.

There is no gold standard method to measure adherence. ${ }^{20}$ Self-reported adherence measures are sometimes said to overestimate adherence because of selfpresentation and recall bias, but a meta-analysis has shown that this is not always the case. ${ }^{20}$ Instructions in the questionnaire were formulated to encourage patients to answer truthfully and assured the patients that their answers would not affect future care. MARS has been used in many studies of several long-term illnesses, including chronic pain, ${ }^{21}$ asthma, ${ }^{7}$ secondary prevention of coronary heart disease ${ }^{9}$ and stroke. ${ }^{19}$ The only other option for measuring adherence would have been prescription refill data, but because Swedish prescriptions generally cover a time period of 3 months, only patients

Table 6 Correlation matrix for different scales used to test beliefs about medicines. Spearman's correlation coefficient ( $p$ Value)

\begin{tabular}{|c|c|c|c|c|c|}
\hline & BMQ-Necessity & BMQ-Concern & BMQ-Overuse & BMQ-Harm & BMQ-Benefit \\
\hline BMQ-Necessity & 1 & & & & \\
\hline BMQ-Concern & $-0.075(0.080)$ & 1 & & & \\
\hline BMQ-Overuse & $-0.226(<0.001)$ & $0.434(<0.001)$ & 1 & & \\
\hline BMQ-Harm & $-0.185(<0.001)$ & $0.444(<0.001)$ & $0.558(<0.001)$ & 1 & \\
\hline BMQ-Benefit & $0.315(<0.001)$ & $-0.287(<0.001)$ & $-0.322(<0.001)$ & $-0.362(<0.001)$ & 1 \\
\hline
\end{tabular}


who did not buy a drug at all within the 3 months of having their stroke (primary non-adherence) would be classified as non-adherent. The proportion of primary non-adherence has been shown to be low (4-11\%) for secondary prevention of stroke. ${ }^{22}$ Questions on adherence were not directed towards specific drugs or treatments and if patients were selectively adherent this was not captured. The cross-sectional design of this study made it impossible to draw conclusions about causality or to measure changes in behaviour.

In a previous study, non-adherence was found to be higher in non-responders compared to responders. ${ }^{23}$ Because adherence was self-reported in this study, nonadherence could not be estimated for non-responders. However, according to data from the stroke register nonresponders more often reported poor general health or depression, more often had had a previous stroke and more often were living alone. There was a larger proportion non-adherent patients among those with a history of stroke compared to first-time strokes. Patients with a history of stroke might have different opinions or perceptions about stroke at this early point after stroke (3 months). With the larger proportion of patients with a previous stroke among non-responders, this could have affected the results on illness perceptions. There could also have been other differences between responders and non-responders that were not tested in this study that could have affected the results.

In a study from the UK on predictors of adherence to secondary preventive treatment after stroke, associations between BMQ-specific (Necessity and Concern) and adherence were tested. Statistically significant associations were found with subscale Concern. ${ }^{19}$ A study on secondary prevention of coronary heart disease found adherence to be related to BMQ subscales Necessity and Concern. ${ }^{9}$ Several studies have also shown similar results with stronger associations between adherence behaviour and beliefs about medicines than with illness perceptions. ${ }^{7-9}$ This is also in line with the extended self-regulatory model according to which illness perceptions could be directly related to adherence but also, and often stronger, indirectly through associations between illness perception and beliefs about medicines. ${ }^{21}$ The full model has not been tested in this study. This study was performed in Sweden, and although different personal beliefs sometimes reflect cultural differences the associations found in this sample were consistent with results from studies in other countries. ${ }^{8} 924$

In this study MARS scores were dichotomised, but in some studies they have been used as a continuous variable. The chosen cut-off allowed adherent patients to answer 'rarely' on two questions or 'sometimes' on one and this cut-off has been used in other studies. ${ }^{25}$ Changing the cut-off from 22 to 21 or 20 decreased the number of patients classified as non-adherent but only marginally changed the associations between personal beliefs and self-rated adherence.
Self-rated non-adherence in this sample was quite low 3 months after stroke, but in other studies nonadherence has been shown to increase over time. ${ }^{4}$ Declining adherence is, of course, a problem but secondary prevention is also important early after stroke. ${ }^{26}{ }^{27}$ Because the results from this study and other studies showed associations between beliefs about medicines and adherence to treatment, it might be important to incorporate these questions into discussions with patients about preventing further illness. Clinical staff should try to assess patients' views of medicines, not just informing patients about medicines or trying to convince patients to use medicines. Giving patients information and instructions is sometimes considered enough, but information is not the same as education. Patients with negative beliefs about medicines need to be identified, and questions from the BMQ could be used for this. Because preventive drugs are important early after stroke, it is important to identify these patients early. Patients with a history of stroke or patients who have used the drugs for other reasons before stroke could be more inclined to have opinions about stroke and medicines already during hospital stay. However, most patients could briefly, already at discharge from hospital, be asked about their opinion about using preventive drugs. Most interventions that have shown effect on patient adherence to long-term treatments are complex and include combinations of several steps, for example, information, self-monitoring, counselling, supportive care. ${ }^{11}$ These more complex interventions are likely more suitable for follow-up visits to hospitals or primary care visits, possibly led by specially trained nurses or trained clinical pharmacists, then for the acute inpatient phase. Patients' perceptions or behaviours are rarely discussed in clinical guidelines.

In conclusion, although self-rated non-adherence 3 months after stroke was low, associations between patients' beliefs about medicines and non-adherence were seen in this sample of Swedish patients with stroke. Patients' personal beliefs need to be considered when prescribing medicines or trying to improve patients' use of medicines.

Acknowledgements The authors would like to thank all of the patients with stroke who answered the questionnaire and the Riks-Stroke contacts in all 25 hospitals that helped them with sending and collecting the questionnaires. The authors are also thankful to Riks-Stroke for providing the database and to Professor Rune Dahlqvist for his comments on the manuscript.

Contributors MS, ME and ELG contributed to the article by participating in the design, analysis or interpretation of data, revising the manuscript critically and approving the final manuscript. MS and ELG were involved in acquisition of data and drafting of the manuscript.

Funding Riks-Stroke, the Swedish Stroke Register, is funded by the National Board of Health and Welfare and the Swedish Association of Local Authorities and Regions. For this study, the authors received grant support from Västerbotten County Council and the Northern Swedish Stroke Fund.

Competing interests None.

Ethics approval The Ethical Review Board at Umeå University, Sweden, 17 January 2012, Reg. No 2011-375-31M.

Provenance and peer review Not commissioned; externally peer reviewed. 
Data sharing statement No additional data are available.

Open Access This is an Open Access article distributed in accordance with the Creative Commons Attribution Non Commercial (CC BY-NC 3.0) license, which permits others to distribute, remix, adapt, build upon this work noncommercially, and license their derivative works on different terms, provided the original work is properly cited and the use is non-commercial. See: http:// creativecommons.org/licenses/by-nc/3.0/

\section{REFERENCES}

1. Socialstyrelsen. Nationella riktlinjer för strokesjukvård 2009-Stöd för styrning och ledning (National guidelines for stroke care 2009) (in Swedish). Stockholm: The Swedish National Board of Health and Welfare, 2009.

2. World Health Organization. Adherence to long-term therapies: evidence for action. Geneva: World Health Organization, 2003.

3. DiMatteo MR, Giordani PJ, Lepper HS, et al. Patient Adherence and Medical Treatment Outcomes: A Meta-Analysis. Med Care 2002;40:794-811.

4. Glader E-L, Sjölander M, Eriksson M, et al. Persistent use of secondary preventive drugs declines rapidly during the first 2 years after stroke. Stroke 2010;41:397-401.

5. Jin J, Sklar GE, Oh VMS, et al. Factors affecting therapeutic compliance: a review from the patient's perspective therapeutics and clinical risk management. 2008;4:269-86.

6. Leventhal H, Diefenbach M, Leventhal E. Illness cognition: using common sense to understand treatment adherence and affect cognition interactions. Cogn Ther Res 1992;16:143-63.

7. Horne R, Weinman J. Self-regulation and self-management in asthma: exploring the role of illness perceptions and treatment beliefs in explaining non-adherence to preventer medication. Psychol Health 2002;17:17-32.

8. Ross S, Walker A, MacLeod MJ. Patient compliance in hypertension: role of illness perceptions and treatment beliefs. J Hum Hypertens 2004; 18:607-13.

9. Byrne M, Walsh J, Murphy AW. Secondary prevention of coronary heart disease: patient beliefs and health-related behaviour. J Psychosom Res 2005;58:403-15.

10. Horne R. Beliefs and adherence to treatment: the challenge for research and clinical practice. In: Halligan P, Aylward M, ed. The power of belief. Oxford: Oxford University Press, 2006:115-36.

11. Haynes RB, Ackloo E, Sahota N, et al. Interventions for enhancing medication adherence. Cochrane Syst Rev 2008;(2):CD000011.

12. Asplund K, Hulter Åsberg K, Appelros $\mathrm{P}$, et al. The Riks-Stroke story: building a sustainable national register for quality assessment of stroke care. Int J Stroke 2011;6:99-108.
13. Broadbent E, Petrie KJ, Main J, et al. The Brief Illness Perception Questionnaire. J Psychosom Res 2006;60:631-7.

14. Horne R, Weinman J, Hankins M. The beliefs about medicines questionnaire: the development and evaluation of a new method for assessing the cognitive representation of medication. Psychol Health 1999;14:1-24.

15. Horne R, Frost S, Hankins M, et al. 'In the eye of the beholder': pharmacy students have more positive perceptions of medicines than students of other disciplines. Int J Pharm Pract 2001:9:85-9.

16. Mahler C, Hermann K, Horne R, et al. Assessing reported adherence to pharmacological treatment recommendations. Translation and evaluation of the Medication Adherence Report Scale (MARS) in Germany. J Eval Clin Pract 2010; 16:574-9.

17. Tavakol M, Dennick R. Making sense of Cronbach's alpha. Int J Med Educ 2011;2:53-5.

18. Horne R, Weinman J. Patients' beliefs about prescribed medicines and their role in adherence to treatment in chronic physical illness. $J$ Psychosom Res 1999;47:555-67.

19. O'Carroll R, Whittaker J, Hamilton B, et al. Predictors of adherence to secondary preventive medication in stroke patients. Ann Behav Med 2011;41:383-90.

20. DiMatteo MR. Variations in patients' adherence to medical recommendations: a quantitative review of 50 years of research. Med Care 2004;42:200-9.

21. Nicklas LB, Dunbar M, Wild M. Adherence to pharmacological treatment of non-malignant chronic pain: the role of illness perceptions and medication beliefs. Psychol Health 2010; 25:601-15.

22. Sjölander M, Eriksson M, Glader E-L. Few sex differences in the use of drugs for secondary prevention after stroke: a nationwide observational study. Pharmacoepidemiol Drug Saf 2012; 21:911-19.

23. Gadkari AS, Pedan A, Gowda N, et al. Survey nonresponders to a medication-beliefs survey have worse adherence and persistence to chronic medications compared with survey responders. Med Care 2011;49:956-61.

24. Menckeberg TT, Bouvy ML, Bracke M, et al. Beliefs about medicines predict refill adherence to inhaled corticosteroids. J Psychosom Res 2008;64:47-54

25. Mårdby A-C, Åkerlind I, Jörgensen T. Beliefs about medicines and self-reported adherence among pharmacy clients. Patient Educ Couns 2007;69:158-64.

26. Sanossian N, Ovbiagele B. The risk of stroke within a week of minor stroke or transient ischemic attack. Expert Opin Pharmacother 2008;9:2069-76.

27. Field T, Benavente O. Current status of antiplatelet agents to prevent stroke. Curr Neurol Neurosci Rep 2011;11:6-14. 